\title{
Beyond the Margins: Evaluating the Support for Multicultural Education within Teachers' Editions of U.S. History Textbooks
}

\section{Author: Christine Rogers Stanton}

This is an Accepted Manuscript of an article published in Multicultural Perspectives Non Nomber 20, 2015, available online: http://www.tandfonline.com/10.1080/15210960.2015.1079491.

Stanton, C. R. (2015). Beyond the margins: Evaluating the support for multicultural education within teachers' editions of U.S. history textbooks. Multicultural Perspectives, 17(4), 180-189, doi: 10.1080/15210960.2015.1079491. 
Beyond the Margins: Evaluating the Support for

\section{Multicultural Education within Teachers' Editions of U.S. History Textbooks \\ Christine Rogers Stanton \\ Montana State University}

Christine Rogers Stanton, Department of Education, Montana State University, Bozeman, Montana.

Correspondence concerning this paper should be addressed to Christine Rogers Stanton, Department of Education, Montana State University, Bozeman, MT 59717. Email:

christine.rogers1@montana.edu 


\begin{abstract}
Although previous research has described analysis of history textbooks in terms of multicultural education, limited attention has been given to teacher only resources, such as the "wraparound features" of teachers' editions. The study highlighted in this article applies critical discourse analysis to explore the potential for teachers' editions to support Culturally Sustaining/Revitalizing Pedagogy (McCarty \& Lee, 2014). The results, which are framed by the approaches to multicultural education identified by Sleeter and Grant (2009), demonstrate that today's teachers' editions frequently marginalize Indigenous peoples, experiences, and histories both spatially and literally through uncritical acceptance of the dominant culture narrative (i.e. "business as usual") or assimilationist orientations (i.e. "teaching the culturally different" or "human relations"). The article concludes with implications for scholarly practice and classroom pedagogy.
\end{abstract}




\section{Beyond the Margins: Evaluating the Support for}

\section{Multicultural Education within Teachers' Editions of U.S. History Textbooks}

As Denzin (2008) notes, if our aim is to advance social justice, there is an urgent need to "disrupt conventional narratives and conventional history... to better understand how racism and social injustice have been seamlessly woven together" (p. 119). Such disruption demands an awareness of the shortcomings of the conventional version of history, but it also requires an attention to pedagogical action.

Despite the extensive research into the curricular representations of Native ${ }^{1}$ and other historically marginalized peoples within student textbooks (e.g. Buras, 2008; Fixico, 1997; Loewen, 1995, 2010; Sanchez, 2007; Stenhouse, 2009), limited attention has been given to the pedagogical features within teachers' editions of textbooks (Lavere, 2008; Levstik, 2008). This research gap is troubling, given that teachers continue to rely on teachers' editions (Brenner \& Hiebert, 2010; Whitney, Golez, Nagel, \& Nieto, 2012).

The purpose of this article is to consider the potential for teachers' editions to support culturally sustaining/revitalizing pedagogy (CSRP). Many teachers' editions include a view of the student text, with margins containing additional teacher-only "wraparound features"resources, explanations, and activity ideas. To allow for depth of analysis and use of examples, this study focused on review of wraparound features related to the teaching of and about Indigenous histories. The project was guided by the question: How effectively do wraparound features support CSRP?

\footnotetext{
${ }^{1}$ Although it is most appropriate to refer to Indigenous peoples according to their individual tribal affiliations, this study uses language aligned with the discourse of the teachers' editions to demonstrate tendencies to over-generalize and - in rare cases - the decision to focus on specific groups. When describing shared theoretical and pedagogical implications, "Indigenous" and "Native" are used interchangeably to emphasize collective solidarity among Indigenous scholars and educators.
} 


\section{Culturally Sustaining/Revitalizing Pedagogy}

To explore this question, it is important to define CSRP and understand how it is situated within the broader field of multicultural education. Since the mid-1990's, there has been a call for pedagogy that engages teachers in the process of shifting multicultural education from theory to practice. In 1995, Gloria Ladson-Billings called for “culturally relevant pedagogy,” which argued for "an ability to develop students academically, a willingness to nurture and support cultural competence, and the development of a sociopolitical or critical consciousness" (p. 483). In 2000, Geneva Gay released her book, Culturally Responsive Teaching, which recognizes that what teachers do, or do not do, influences the effectiveness of multicultural education. In other words, how teachers enact curriculum — the pedagogy — matters just as much, or more than, the curriculum itself.

In 2014, Ladson-Billings revisited her 1995 work and called for a dynamic multicultural education theory that responds to the changing demands of practice and research. Specifically, she emphasized the value of Paris' (2012) view of culturally sustaining pedagogy as a means to confront the tendency for "a static conception of what it means to be culturally relevant" (Ladson-Billings, 2014, p. 77). Culturally sustaining pedagogy reaches beyond detached tolerance and responsiveness in order to iteratively and actively support learners in "sustaining the cultural and linguistic competencies of their communities while simultaneously offering access to dominant cultural competence" (Paris, 2012, p. 95).

McCarty and Lee (2014) expand upon Paris' work: They argue for culturally sustaining and revitalizing pedagogy (CSRP), or a theoretically-grounded practice that seeks to reinvigorate those traditional beliefs and languages that have been forcibly oppressed within or eliminated from Indigenous communities (McCarty \& Lee, 2014). Critical Indigenous scholars emphasize 
that researchers, educators, and curriculum authors should honor experiential narrative, relationality, story-sharing, and collective memory in order to revitalize Native knowledges and ways of knowing (Archibald, 2008; Bishop, 2008; Brayboy, 2005; Grande, 2004; Smith, 1999).

To further frame analysis related to CSRP and offer a model for practical application, the project described in this article applies the work of Sleeter and Grant (2009), who suggest that approaches to teaching about culture can be categorized. Traditionally, the Business as Usual view of U.S. history education has reinforced the dominant culture historical narrative and "deficit theories" (Nieto, 2004, p. 3), which have "viewed the languages, literacies, and cultural ways of being of many students and communities of color as deficiencies to be overcome in learning the demanded and legitimized dominant language, literacy, and cultural ways of schooling" (Paris, 2012, p. 93). Instead of sustaining or revitalizing culture, a Business as Usual perspective seeks to oppress, silence, or eliminate diversity.

Beyond the Business as Usual view, which Sleeter and Grant view as a rejection to multicultural education rather than a path to it, there are several approaches to multicultural education. The first approach, Teaching the Culturally Different, continues to rely heavily upon deficit orientations in order to encourage assimilation of multicultural perspectives into the dominant culture. For example, educators who engage with this approach may diminish and separate the experiences of Native peoples from the experiences of Euro-Americans. This approach recognizes diverse experiences, but only as undesirable elements, therefore bolstering “resource pedagogies" (Paris, 2012, p. 94). Such efforts endeavor to provide the tools needed by predominantly White teachers to close the achievement gap between subgroups of students. Paris (2012) identifies the goal of "difference approaches" as striving "to bridge toward the 
dominant with little attention to maintaining [or, as McCarty and Lee would suggest, revitalizing] the heritage and community practices of students and families” (p. 94).

The second approach, Human Relations, encourages a view of diversity as beneficial for broad social advancement. Teachers who use this approach promote values of mutual respect and intercultural competence, especially within the context of peace, harmony, and communication. This approach recognizes and values multiculturalism only in basic ways, since it emphasizes sameness instead of appreciating difference. As a result, the Human Relations approach does not necessarily promote the "valuing and maintenance of our increasingly multiethnic and multilingual society" (Paris, 2012, p. 94). Furthermore, the Human Relations approach often privileges Eurocentric educational goals that center upon passive tolerance, globalization, and productivity. In many ways, the culture that is best sustained or revitalized through the Human Relations approach is the dominant culture.

Sleeter and Grant (2009) note that more responsive educators might use the model of Single Group Studies to teach about U.S. history or other subjects. For example, Single Group Studies educators might provide a course or unit focusing on Native histories. Unlike the Business as Usual or Teaching the Culturally Different perspectives, this approach does not necessarily rely upon the historical interaction between Native and non-Native peoplesindependent histories are highlighted. If it is applied with depth, the Single Group Studies approach offers the potential to sustain or even revitalize historically marginalized cultures. However, teachers claiming to use the Single Group Studies approach may present a superficial view of a specific cultural group. It is fairly common, for example, to describe traditions in a way that confines cultural experiences to the distant past, instead of seeking to sustain or revitalize them. 
The fourth approach described by Sleeter and Grant (2009), Multicultural Education, values diversity of experience throughout the curriculum. Teachers who use this approach draw upon a variety of curriculum materials and sources, and they use multiple instructional strategies and assessment types. For example, teachers might teach using timelines that detail parallel histories of Europeans, Euro-Americans, and several specific tribes. The Multicultural Education approach, therefore, seeks to recognize and sustain multiple cultural histories and experiences simultaneously. Paris (2012) emphasizes that valuing both "within-group cultural practices" and "across-group cultural practices" (p. 95) advances the teaching and learning of all students, not just students of color. However, the Multicultural Education approach may not actively strive to revitalize historically oppressed or marginalized experiences, given its efforts to equitably advance multiple narratives.

The final model, Multicultural Social Justice Education, best aligns with the vision of culturally sustaining and revitalizing pedagogy. These teachers engage students in the process of challenging historical norms and existing power structures in order to advance local and global change, promote critical thinking, and validate diverse community funds of knowledge (González, Moll, \& Amanti, 2005). For example, Multicultural Social Justice teachers might guide youth as they seek out oral counter-narratives. Such work sustains cultural knowledges, while revitalizing cultural ways of knowing by engaging youth as co-participants in the storying process with elders and community members.

\section{Data Sources and Methods}

The American Textbook Council (ATC) synthesizes information shared by major textbook publishers with textbook adoption data from states and large school districts. For this study, the ATC's list of "widely adopted history textbooks" (American Textbook Council, 
$2011^{2}$ ) provided the titles of five U.S. history textbooks frequently used at the eleventh grade level. Based on that list, the project included the teachers' editions of Glencoe/McGraw Hill's American Vision (Appleby, Brinkley, Broussard, McPherson, \& Ritchie, 2010), Holt McDougal's American Anthem (Ayers, Schulzinger, de la Teja, \& White, 2009), Prentice Hall/Pearson's A History of the United States (Boorstin \& Kelley, 2007), Prentice Hall/Pearson's Pathways to the Present (Cayton, Perry, Reed, \& Winkler, 2007), and Holt McDougal's The Americans (Danzer, Klor de Alva, Krieger, Wilson, \& Woloch, 2012). These titles are often included in research that analyzes U.S. history textbook discourse (e.g. Alridge, 2006; Chick, 2006; Hess \& Stoddard, 2007; Sanchez, 2007). To support readability, abbreviated versions of the titles (i.e. Vision, Anthem, A History, Pathways, and Americans) are used throughout this article.

Within critical curriculum inquiry, scholars evaluate overt messages (e.g. selection or deselection of events, use of quotations or images, etc.) as well as messages that support the “hidden curriculum” (Freire, 1972/2000). In this study, van Leeuwen's (2008) tools for critical discourse analysis guided focused review of the wraparound features. In particular, attention was given to the use of language for purposes of exclusion (e.g. the omission of Indigenous perspectives), role allocation (e.g. the passivation of Native peoples and the activation of nonNative heroes), collectivization (e.g. overgeneralizing Native peoples or beliefs), identification (e.g. Native peoples are defined by "fate"), and impersonalization (e.g. descriptions of specific Native peoples are minimized).

To allow focused comparison across the teachers' editions, this study considered textbook sections devoted to the period commonly referred to as "Westward Expansion"

\footnotetext{
${ }^{2}$ The American Textbook Council no longer lists the most popular textbooks. The titles chosen for this study were determined based on the list published on the ATC website through late 2013.
} 
(approximately 1860-1900). This section was selected for both convenience (i.e. all five textbooks included a chapter section devoted to the topic) and potential impact (i.e. historical representations of Plains tribes continue to influence teacher and student beliefs about Native peoples today). Since all five textbooks include such sections, this era offered the most substantive content related to Native history following contact with Europeans and provided a vehicle for analysis regarding the support for multicultural education across publishers.

For the initial phase of analysis, a holistic review devoted attention to author biographical information, organizational strategies, and discussion of the limitations of the textbook, if available. The next phase of review consisted of line-by-line and situated discursive analysis of the wraparound features in the focus sections of each textbook using van Leeuwen's tools for critical discourse analysis. Finally, the results were categorized according to the approaches to multicultural education identified by Sleeter and Grant (2009) and considered within the context of recommendations made by critical Indigenous scholars, particularly as situated within CSRP.

\section{Results}

Together, the "Westward Expansion" sections of the teachers' editions of the five textbooks offer 144 wraparound items that provide information about Native peoples, histories, or perspectives. The majority of the wraparound features support Business as Usual, Teaching the Culturally Different, and Human Relations (see Figure 1), while fewer support Single Group Studies, Multicultural Education, and Multicultural Social Justice Education (see Figure 2).

Business as Usual. In twenty-three cases (approximately $16 \%$ of the analyzed wraparound references to Native peoples), the teachers' editions in this project display a resistance to multicultural education pedagogy. The analysis revealed three themes that support Business as Usual. 
The disappeared. One key indicator of the Business as Usual stance is the suggestionsometimes direct and sometimes more subtle - that Native culture and resistance ended in the late 1800 s. For example, Anthem's authors direct teachers to ask the question "How did Native American resistance to white settlement end?" (p. 442). The suggested answer notes that Native peoples "were moved to reservations, captured, or defeated" (p. 442). In this example, the use of past tense limits discussion about continued — and ongoing — resistance efforts. Native actors are positioned within the distant past, excluding Native peoples from the $20^{\text {th }}$ and $21^{\text {st }}$ centuries.

White settler stories. Textbook authors frequently privilege Eurocentric narratives and perspectives through omission of Native accounts and/or over-reliance on settler values. For example, Anthem's authors direct teachers to "Tell students that in this chapter they will learn how the American West was transformed from unsettled territories to ranches, farms, and towns" (p. 436). In this case, the authors' discursive choices demonstrate inherent bias against "unsettled territories" in favor of Eurocentric agrarian values.

The savage Other. Several wraparound features include stereotypical and inaccurate language. For example, The Americans refers to the Wounded Knee massacre, where well over 100 Native peoples - mostly unarmed women and children — were killed, as a "battle" (p. 412). Such a discursive choice is not only inaccurate; it fortifies stereotypical, violent imagery associated with Indigenous histories. A History uses the term "cult" to refer to the Ghost Dance, a complex intertribal effort to resist cultural genocide (p. T21). Through this linguistic description, Native peoples are assigned roles associated with "misplaced obsession" or “sinister” beliefs (Oxford Dictionary, n.d.). 
Teaching the Culturally Different. Analysis of the teachers' editions included in this study revealed $28.5 \%$ of wraparound features support the Teaching the Culturally Different approach to multicultural education. Two themes that support this approach emerged.

Inevitable conflict. Each of the textbooks emphasizes fundamental and irreconcilable differences between Native cultures and dominant culture. For example, the Bellringer activity in Pathways encourages teachers to "Direct the class to list the areas of conflict that were most likely to arise between natives and new settlers" (p. 491). In The Americans, teachers are encouraged to "Have students think about those aspects of their culture that might keep the Native Americans and white settlers from living together peacefully" (p. 407). In a Direct Teach Reading Focus feature, Anthem instructs teachers to emphasize, "Native Americans did not believe that land could be owned" (p. 439). This statement oversimplifies, collectivizes, and generalizes diverse and complex views Native peoples have traditionally held, and still hold, regarding land access, ownership, and use.

Americans vs. Other. The discourse used in the teachers' editions suggests that the tensions between Native peoples and Europeans/Euro-Americans were not simply due to conflicting beliefs: The people themselves were/are inherently different. For example, the texts assign dominant culture actors roles as "settlers" (The Americans, p. 405c; Pathways, p. 491; Vision, p. 403), “easterners” (Pathways, p. 491), “whites” (The Americans, p. 411), and “Americans" (Anthem, p. 438). This last choice is particularly interesting, since it clearly distinguishes between "Americans" and "Native Americans." Of the reviewed textbooks, only Vision uses more specific discourse [e.g. “American soldiers” (p. 401), “U.S. army” (p. 401), or "American Calvary" (p. 401)] to highlight variations within dominant culture. 
Human Relations. The analysis demonstrates that today's teachers' editions frequently promote assimilationist orientations (28.5\% of wraparound items support the "human relations" approach). Three themes that support the Human Relations approach emerged.

The way it was. In multiple examples, the authors of the teachers' editions carefully chose language to avoid assigning blame to White settlers, army personnel, or government. For example, teachers are encouraged to help students recognize the "misunderstandings" (Pathways, p. 492) that might lead to conflict. In several cases, teachers are directed to guide students to identify both positive and negative effects of settlement and colonization. For example, in The Americans, a wraparound feature called "Technology in the Classroom" instructs, "Using the computer or pencil and paper, have students make a two-column chart of positive changes and negative changes for Native Americans" (p. 405d).

Money matters. The authors of teachers' editions also justify historical atrocities by noting the economic reasons driving decision-making. For example, an exercise titled "Teach Differentiated Instruction" in Vision suggests teachers "have students research the geography and mineral resources of the Black Hills. Have students use their findings to write a one-page essay explaining why white settlers wanted to remove Native Americans from the Black Hills" (p. 399). The Americans encourages teachers to lead a discussion that emphasizes the economic incentives tied to settlement: "Have students consider what are some of the most important jobs that would accompany the settlement of a wild and unsettled frontier region" (p. 407). Note that this brief example also illustrates the tendency of textbook authors to draw upon stereotypical, and inaccurate, language ("wild and unsettled frontier"). While it is undeniable that economic motives drove, and continue to drive, many oppressive practices, the authors exclude other motivations from the discussion. 
Let's get along. History textbooks and activities that use the Human Relations approach often urge teachers and students to identify compromise to historical and cultural conflicts. For example, the wraparound feature "Connecting with History and Conflict" (p. 493) in the Pathways text encourages teachers to guide students through a negotiation exercise:

Tell students that they are going to try to negotiate an agreement between the Native American tribes and the United States government... Have both groups consider the causes and effects of actions taken by Native Americans to expand economic opportunities and political rights in the United States. When the two groups come together, they should try to find a way to work out their differences. (p. 493) Although compromise grounded in dialogue and mutual respect is important for culturally sustaining pedagogy, it is important to recognize that-historically_- "compromise" has typically favored European and Euro-American interests first and foremost. Furthermore, over-emphasis on compromise perpetuates a myth of objectivity, given its suggestion that teachers and students can simply set aside their own biases in order to evaluate complex historical events. Focusing on compromise and tolerance may obstruct higher level, critical questions and additional inquiry. In these cases, the Human Relations approach could discourage student activism and CSRP.

Single Group Studies. The Single Group Studies approach represents a more advanced approach to multicultural education, particularly within history education. Given the tendency of history textbooks to provide a survey of information in superficial ways, textbooks and teachers' editions that include more in-depth information about a group (e.g. Native Americans) or subgroup (e.g. the Lakota) offer the potential for more complex, accurate, and respectful information. Unfortunately, few of the wraparound features (less than 10\%) support the Single 
Group Studies approach. Analysis revealed two themes related to the Single Group Studies approach.

Naming. Drawing teacher and student attention to specific individuals and tribes is the most common Single Group Studies method illustrated within the wraparound features. For example, Vision includes an activity called "Teach Writing Support," which directs teachers to have students write a narrative "about one leading Native American chief, such as Red Cloud, Crazy Horse, or Sitting Bull” (p. 399). Pathways includes a "Connecting with History and Conflict" activity, which asks students "to research and write a brief biography of one of the following Native American leaders of the West: Red Cloud, Sitting Bull, Black Kettle, Crazy Horse, Cochise, or Geronimo" (p. 493). Such activities endeavor to humanize, rather than impersonalize, Native actors.

Similarly, features that support the Single Group Studies approach encourage accuracy by noting inter- and intra-tribal diversity. For example, the "More About... The Battle of Little Bighorn" note in the teachers' edition of The Americans explains:

At Sitting Bull's camp in the valley of the Little Bighorn, about 2,000 Indians had gathered. A Cheyenne woman later said, 'There were more Indians... than I ever saw anywhere together.' Custer's scouts were Crow. The scouts tried to warn Custer of the size of the Indian encampment, but Custer replied, 'I guess we'll get through them in one day.' (The Americans, p. 412)

Most often, textbook authors generalize Native peoples, instead of referring to specific tribal groups or individuals. In the above example, the authors try to distinguish between tribal groups. They suggest differences in alliances between Cheyenne (who were camping with Sitting Bull's people, the Lakota) and Crow (who were scouting for Custer) peoples. As this example 
illustrates, not all Native peoples fought against the Calvary at Little Big Horn, and not all Native peoples had the same motivations, experiences, and perspectives.

Contemporary connections. Several of the wraparound features that support Single Group Studies encourage students to learn about the continued, active presence of specific Native peoples. For example, the Pathways authors include a "Connecting with Culture" activity that encourages students to explore the historical life and continued influence of the "Sioux":

Tell students to research the Sioux. Have them investigate how the Sioux lived in the nineteenth century and how their culture has survived in the twenty-first century. How has their way of life changed over the years? Where do the Sioux live? What is their approximate population? After students complete their research, have them deliver an oral presentation on their findings. (Pathways, p. 495)

This activity focuses student attention on the "Sioux," which is preferable to overgeneralizing across very different tribal groups. However, this exercise also demonstrates challenges related to using the Single Group Studies approach, in that no explanation or clarification of the selected term ("Sioux") is provided to teachers or students. For example, the authors do not suggest that they have selected the term to be inclusive of the various Siouan groups, including the Lakota, the Dakota, etc. In addition, the authors do not note that in certain Native communities the use of "Sioux" is not only overly generalizing — it is offensive.

Multicultural Education. At its core, the Multicultural Education approach encourages teachers and students to consistently value multiple perspectives. Several of the teachers' editions demonstrate an attempt to support Multicultural Education, with twenty-two of the wraparound features (15\%) supporting this more advanced approach. Analysis of the features demonstrated two themes related to Multicultural Education. 
Rethinking assimilation. Textbook authors that use the Multicultural Education approach recognize the importance of critical engagement with diverse perspectives. For example, the outline of a "Technology in the Classroom" activity in The Americans notes, "Students will visit the online exhibition at the Smithsonian's National Museum of the American Indian. There, they will use visual and written sources to explore the impact of forced assimilation on Native Americans" (p. 405d). This activity engages students with research and diverse primary sources — including Native sources often excluded in textbooks. Through this activity, the authors emphasize the reality that many assimilation efforts were forced. Similarly, a "Reading Comprehension" activity in Pathways emphasizes the negative impacts of assimilation: "Reeducation forced elders to give up their traditions and beliefs; schools for Native American children instilled only 'white' cultural ideas” (p. 497).

Critical thinking. In addition, authors who support the Multicultural Education approach promote critical thinking activities for all students - not only as part of extension exercises or as background information to share if students raise specific questions. For example, Anthem includes a "Teach the Main Idea" activity that encourages students to apply what they have learned:

Organize the class into mixed-ability pairs. Have each pair write two newspaper headlines that support key changes in U.S. government policy toward Native Americans during the mid-1800s. Then have each pair write two headlines that oppose proposed policy changes. (Anthem, p. 438)

This example has the potential to support Multicultural Education for several reasons. First, it engages all students in thinking critically about cultural information. Second, it uses an authentic task to support higher-level thinking, engagement, and application. Finally, it promotes 
awareness of multiple perspectives, as opposed to excluding all but the dominant culture perspective.

\section{Multicultural Social Justice Education. The Multicultural Social Justice Education} approach represents the pedagogical model that is the most supportive of the goals of culturally sustaining and revitalizing education. However, examples of such practice are extremely limited. This study identified only three examples, or $2 \%$ of all reviewed wraparound features in the focus sections. Analysis of these three features suggests two themes.

Honoring diverse ways of knowing. Only one teachers' edition addressed the limitations of written text in a way that demonstrates respect for experiential narrative, story-sharing, and collective memory. Specifically, the Pathways teachers' edition includes a "Background: A Diverse Nation" note for teachers that elevates attention to the importance of oral histories: In studying native cultures historians face a major obstacle — a lack of documents written by Native Americans. Historians must rely on records left by white people. At best these documents reflect what the white people thought the native people wanted to say. There is, however, a rich oral tradition that provides insight into Native American history. Elders shared their stories with their descendants, and in so doing preserved important events, concepts, and beliefs. This oral tradition serves as a fertile source of understanding of the Native American experience. (Pathways, p. 493)

This example is notable for several reasons. First, it acknowledges the inherent bias of written documents, which "reflect what the white people thought the native people wanted to say." Rarely do the wraparound features or textbooks include information about the complex process of translation, from Native language to English and from spoken understanding to written 
documentation. Furthermore, this example demonstrates an effort to view oral histories as relevant and vital, especially within the context of Native history.

Despite its efforts, this example remains problematic for several reasons. Through their discursive choices, the authors have suggested that a collectivized Native experience exists/existed, and that non-Natives can come to "understand" that experience by listening to oral histories. This over-simplifies the nature of storytelling and the complexity of collective memory. Additionally, this example demonstrates the tendency of authors to make such generalizations for all cultural groups, not just Native peoples, since all "white people" are grouped together. However, this example provides a starting place for educators striving to advance social justice in that it offers oral histories as a legitimate and essential source of information about Native experiences.

Critique of dominant culture actors. The remaining Multicultural Social Justice Education examples interrogate the motivations of dominant culture individuals and groups. For example, a "Reading Like a Historian" activity encourages teachers and students to critique the motivations of a group whose members were frequently regarded as allies of Native peoples:

Consider a statement by a group calling itself "The Friends of the Indian," which convened every summer, starting in 1883, in Lake Monhonk, New York. Members traveled considerable distances, volunteering their time and financial resources, to deliberate over the fate of the American Indian. Members were socially prominent, uniformly white, and often rich. What brought them together was a heightened social conscience and a desire to ease human suffering. They were acquainted with the deplorable conditions on the reservation and believed that the way to help Native Americans was to make them become more like white socialites-which meant, 
according to their beliefs, "get[ting] the Indian out of the blanket and into trousers - and trousers with a pocket in them, and with a pocket that ache[d] to be filled with dollars!"

(Anthem, p. 435d)

Although this example provides teachers with information regarding the complexity of activism and advocacy during this historical period, and although it highlights the Eurocentric values underlying the motivations of the actors, it remains pedagogically problematic since it appears in a section that is simply framed as supplemental information for the teacher. How, or if, the information informs classroom practice remains unclear.

\section{Discussion}

As this study reveals, the wraparound features in teachers' editions of junior level U.S. history textbooks marginalize — spatially and literally_-Indigenous experiences. The authors of teachers' editions rarely support culturally sustaining pedagogy, and they advance CSRP even less frequently. Analysis demonstrates that authors most frequently promote uncritical acceptance of the dominant culture narrative or assimilationist orientations, while neglecting important Indigenous elements such as experiential narrative, story-sharing, and collective memory. Little attention is given to Native sources or to the validation of oral history and storytelling.

Pedagogically, several areas of concern emerged throughout the analysis. First, activities that offer the potential to engage students in multicultural education are frequently framed in terms of extension or enrichment opportunities. The message is clear: With the pressure to cover the content, it is just not possible to include high quality multicultural education for all students all the time. The wraparound features further reinforce the idea that the experiences of the Other are separate from the mainstream curriculum through their limited view of intertribal diversity. 
By focusing on only a few well-known tribal groups (e.g. the Iroquois, Cherokee, Sioux, Navajo, and Apache $)^{3}$, the authors send messages that other tribal nations are nonexistent or unimportant.

As a second area of concern, the features rarely offer meaningful guidance for teachers. They often appear as blocks of text in the margins, without additional information regarding classroom application. Are the features meant to guide teachers' own research and/or selection of supplemental resources? Should they inform class discussions or other activities? Or, is the marginalized text simply a bit of unusual trivia the authors believe is too complex to include in student texts? Given the research that shows today's learners are underprepared for the higherlevel thinking, especially as related to multiple perspectives, such ambiguity is problematic.

Third, marginalization and ambiguity also demonstrate the tendency of authors to avoid politicized discourse. While such avoidance may appeal to a broad audience/market, it is in direct opposition to the discomfort and disequilibrium that, according to transformative learning theorists, is inherent to learning (Taylor, 2007). In particular, a "pedagogy of discomfort" can advance learning about injustices (Zembylas, 2015). Therefore, by claiming a neutral position that discourages discomfort, the textbook authors actually resist effective, advanced approaches to multicultural education.

\section{Conclusion: Implications for Practice}

The results of this study challenge the assumption that today's curriculum materials, including teachers' editions, have evolved to support multicultural education theory. Textbook authors could improve their textbooks by considering the 4 R's highlighted Indigenous scholars:

\footnotetext{
${ }^{3}$ It is important to note that several of these "tribes" are confederations consisting of multiple tribes, bands, etc. The fact that textbook authors and publishers omit such clarifications leads teachers to ignore the diversity within these larger groups. In addition, the authors and publishers typically use the dominant culture names (e.g. "Sioux") for these groups, which-as mentioned above - can be problematic.
} 
respect, responsibility, reciprocity, and relationships (McCarty \& Lee, 2014). For example, authors could limit the use of settler and capitalist discourse in activity prompts to better respect Native ways of knowing. Rather than encouraging teachers to privilege concepts of surrender and compromise, authors could include Native primary sources that reflect resistance. Such changes would demonstrate an effort to revitalize Indigenous perspectives and counternarratives.

In order to confront the biases within textbooks, teachers can promote critical thinking about narratives and counter-narratives. For example, teachers can engage students in community-centered, oral history research into the experiences of local Indigenous peoples. Such inquiry immerses students in learning about the complexities and dynamism of Indigenous experiences, instead of adding those experiences to the mainstream curriculum in superficial and passive ways. This research activity also confronts the pan-Indianism that is common within the textbooks, since it focuses attention on local Indigenous history and experience. Furthermore, community-centered research builds higher order thinking skills and offers support to teachers who are themselves learning about Native histories and experiences. Such activities engage students and teachers in exploring their own and others' discomfort through dialogue and interpersonal communication.

CSRP also requires accountability to the Native community (McCarty \& Lee, 2014), so schools should work to engage Indigenous leaders in evaluation, professional development planning, and other decision-making processes. Since the majority of today's teachers are nonNative and are likely unfamiliar with Indigenous knowledges and ways of knowing, effective CSRP depends upon teacher learning. This assumes that teachers want to practice CSRP and that they have the time, resources, and support needed to learn how to do so. One way to provide 
both support and accountability is to pair teachers with mentors from the tribal communities. It is important to recognize that, given the legacy of forced relocation, community-centered research and cultural mentorship programs may need to expand beyond the immediate, contemporary, physical context. Communication technologies such as email and Skype, and internet-based resources such as those found on websites such as Teaching Tolerance (www.tolerance.org), Oyate (oyate.org), and Montana's Indian Education for All (http://opi.mt.gov/programs/indianed/IEFA.html) can offer materials, pedagogical guidance, and opportunities for networking.

Accountability can also be advanced through standards reform. Cultural standards, such as Montana's Indian Education for All (IEFA) Essential Understandings, provide a framework for teachers who are unfamiliar or uncomfortable with Indigenous histories. IEFA has demonstrated the potential for state-level mandates to increase teachers' awareness of the need for multicultural education (Carjuzaa, Jetty, Munson, \& Veltkamp, 2010), although additional research is needed to determine how effectively teachers apply IEFA to textbook-based instruction, since most textbooks are developed outside of the state of Montana. While the results of the study highlighted in this article can help teachers become aware of the deficiencies of teachers' editions, how teachers address those deficiencies remains an undertaking for future study. Clearly, there is still much work to be done to advance the conversation, scholarship, and practice surrounding the use of teachers' editions as tools for CSRP. 


\section{References}

Alridge, D. P. (2006). The limits of master narratives in history textbooks: An analysis of representations of Martin Luther King, Jr. Teachers College Record, 108(4), 662-686.

American Textbook Council (2011). Widely adopted history textbooks. Retrieved from http://www.historytextbooks.org/adopted.htm

Apple, M. W., \& Christian-Smith, L. K. (Eds.) (1991). The politics of the textbook. New York, NY: Routledge.

Appleby, J., Brinkley, A., Broussard, A. S., McPherson, J. M., \& Ritchie, D. A. (2010). The American vision. Columbus, OH: McGraw Hill.

Archibald, J. (2008). Indigenous storywork: Educating the heart, mind, body, and spirit. Vancouver: UBC Press.

Ayers, E. L., Schulzinger, R. D., de la Teja, J. F., \& White, D. G. (2009). American anthem. New York: Holt, Rinehart, and Winston.

Bishop, R. (2005). Freeing ourselves from neocolonial domination in research: A Kaupapa Maori approach to creating knowledge. In N. K. Denzin \& Y. S. Lincoln (Eds.), The Sage handbook of qualitative research ( ${ }^{\text {rd }}$ ed., pp. 109-138). Thousand Oaks, CA: Sage.

Boorstin, D. J., \& Kelley, B. M. (2007). A History of the United States. Boston: Pearson/Prentice Hall.

Brayboy, B. (2005). Toward a tribal critical race theory in education. The Urban Review, 37(5), 425-446.

Brenner, D. \& Hiebert, E. H. (2010). If I follow the teachers' editions, isn't that enough? Analyzing reading volume in six core reading programs. The Elementary School Journal, $110(3), 347-363$. 
Buras, K. L. (2008). Rightist multiculturalism: Core lessons on neoconservative school reform. New York: Routledge.

Carjuzaa, J., Jetty, M., Munson, M. \& Veltkamp, T. (2010). Montana's Indian Education for All: Applying multicultural education theory. Multicultural Perspectives, 12(4), 192-198.

Cayton, A., Perry, E. I., Reed, L., \& Winkler, A. M. (2007). America: Pathways to the present. Needham, MA: Prentice Hall.

Chick, K. A. (2006). Gender balance in K-12 American history textbooks. Social Studies Research \& Practice, 1(3), 284-290.

Cult. (n.d.). In Oxford Dictionaries. Retrieved from http://www.oxforddictionaries.com/us/definition/american_english/cult

Danzer, G. A., Klor de Alva, J. J., Krieger, L. S., Wilson, L. E., \& Woloch, N. (2012). The Americans. Orlando, FL: Holt McDougal.

Denzin, N. (2008). Interpretive biography. In J. G. Knowles \& A. L. Cole (Eds.), Handbook of the arts in qualitative research (pp. 117-125). Thousand Oaks, CA: SAGE.

Fairclough, N. (1992). Discourse and social change. Malden, MA: Polity.

Fixico, D. L. (1997). Introduction. In D. L. Fixico (Ed.) Rethinking American Indian history. Albuquerque, NM: University of New Mexico Press.

Freire, P. (2000). Pedagogy of the oppressed. New York, NY: Continuum. (Original work published 1972)

Gay, G. (2000). Culturally responsive teaching: Theory, research, \& practice. New York, NY: Teachers College Press.

González, N., Moll, L. C., \& Amanti, C. (2005). Funds of knowledge: Theorizing practice in households, communities, and classrooms. Mahwah, N.J.: L. Erlbaum Associates. 
Grande, S. (2008). Red pedagogy: The un-methodology. In N. K. Denzin, Y. S. Lincoln, \& L. T. Smith (Eds.) Handbook of critical and Indigenous methodologies (pp. 233-254). Los Angeles, CA: Sage.

Hess, D., \& Stoddard, J. (2007). 9/11 and terrorism: "The Ultimate teachable moment" in textbooks and supplemental curricula. Social Education, 71(5), 231-236.

Ladson-Billings, G. (1995). Toward a theory of culturally relevant pedagogy. American Educational Research Journal, 32(3), 465-491.

Ladson-Billings, G. (2014). Culturally Relevant Pedagogy 2.0: A.K.A. the remix. Harvard Educational Review, 84(1), 75-84.

Lavere, D. B. (2008). The quality of pedagogical exercises in U.S. history textbooks. The Social Studies, 99(1), 3-7.

Levstik, L. S. (2008). What happens in social studies classrooms?: Research on K-12 social studies practice. In L.S. Levstik \& C. A. Tyson (Eds.), Handbook of Research in Social Studies Education (pp. 50-62). New York: Routledge.

Levstik, L. S., \& Barton, K. C. (2010). Doing history: Investigating with children in elementary and middle schools (4th ed.). Mahwah, NJ: Lawrence Erlbaum.

Loewen, J. W. (2010). Teaching what really happened: How to avoid the tyranny of textbooks and get students excited about doing history. New York, NY: Teachers College Press.

Loewen, J. W. (1995). Lies my teacher told me: Everything your American history textbook got wrong. New York, NY: Simon \& Schuster.

McCarty, T. L., \& Lee, T. S. (2014). Critical Culturally Sustaining/Revitalizing Pedagogy and Indigenous education sovereignty. Harvard Educational Review, 84(1), 101-124. 
Nieto, S. (2004). Affirming diversity: The sociopolitical context of multicultural education. $\left(4^{\text {th }}\right.$ ed.). Boston: Pearson

Paris, D. (2012). Culturally sustaining pedagogy: A needed change in stance, terminology, and practice. Educational Researcher, 41(3), 93-97.

Sanchez, T. R. (2007). The depiction of Native Americans in recent (1991-2004) secondary American history textbooks: How far have we come? Equity \& Excellence in Education, 40(4), 311-320.

Sleeter, C. E., \& Grant, C. A. (2009). Making choices for multicultural education: Five approaches to race, class, and gender. Hoboken, NJ: John Wiley \& Sons.

Smith, L. T. (1999). Decolonizing methodologies: Research and Indigenous peoples. New York: Zed Books.

Stenhouse, V. L. (2009). Rethinking Thanksgiving. Rethinking Schools, 24(1), 51-55.

Taylor, E. W. (2007). An update of transformative learning theory: A critical review of the empirical research (1999-2005). International Journal of Lifelong Education, 26(2), 175191.

van Leeuwen, T. (2008). Discourse and practice: New tools for critical discourse analysis. Oxford University Press.

Whitney, L., Golez, F., Nagel, G., \& Nieto, C. (2012). Listening to voices of practicing teachers to examine the effectiveness of a teacher education program. Action in Teacher Education, 23(4), 69-76. DOI: 10.1080/01626620.2002.10463090

Zembylas, M. (2015). "Pedagogy of discomfort" and its ethical implications: The tensions of ethical violence in social justice education. Ethics and Education,1-12. DOI: $10.1080 / 17449642.2015 .1039274$ 
